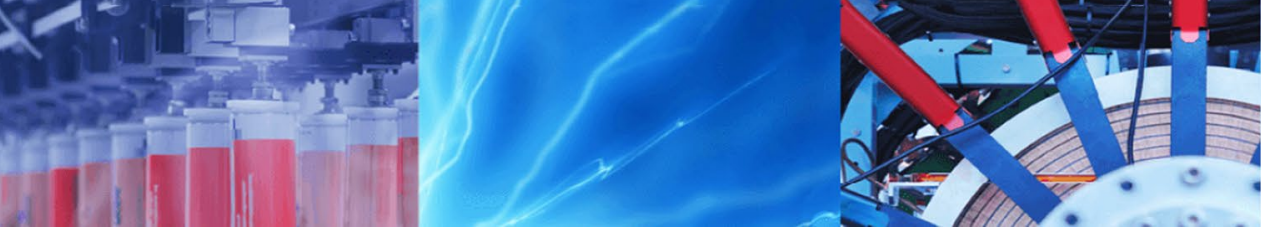

Research Article

\title{
A characterization of different alkali chemical agents for alkaline flooding enhanced oil recovery operations: an experimental investigation
}

\author{
Sherif Fakher ${ }^{1}$ (1) $\cdot$ Hesham Abdelaal ${ }^{2} \cdot$ Youssef Elgahawy $^{3} \cdot$ Abdulmohsin Imqam $^{1}$
}

Received: 22 October 2019 / Accepted: 9 November 2019 / Published online: 16 November 2019

(c) Springer Nature Switzerland AG 2019

\begin{abstract}
Alkaline injection is a chemical enhanced oil recovery method that is used to increase oil recovery by reacting with the crude oil and creating an in situ surfactant. Many chemical agents can be used as an alkali during injection all of which have several advantages and disadvantages. This research focuses on the innate properties of three alkali agents and their ability to alter $\mathrm{pH}$ and temperature downhole. Alkali solutions were prepared with five different concentrations including $0.2,1,2,3$, and $4 \mathrm{wt} \%$. The impact of varying the alkali concentration, monovalent cations manifested in sodium chloride, and divalent cations manifested in calcium chloride was investigated for all three alkalis. The chemical agents investigated include sodium hydroxide, sodium silicate, and sodium carbonate. Results indicated that sodium hydroxide and sodium silicate managed to impact the $\mathrm{pH}$ the most compared to the sodium carbonate. Sodium hydroxide also managed to increase the temperature significantly which is advantageous since it can reduce oil viscosity downhole. Sodium silicate had an advantage of being in liquid state at ambient conditions which makes injecting it downhole much easier compared to the two other alkaline agents. The chemical that was much affected by divalent cations was sodium silicate, which generated a precipitate and thus is not compatible with divalent cations, which are a major composition of most formation water. This research focuses on the innate properties of the alkali agents and the downhole factors that may impact their applicability in different oil reservoirs.
\end{abstract}

Keywords Alkaline injection · Chemical interactions · Chemical agents

\section{Introduction}

In order to recover the maximum amount of hydrocarbons from oil and gas reservoirs economically and safely, several methods may be applied to further mobilize the hydrocarbons [1-5]. Enhanced oil recovery is applied to increase oil recovery from hydrocarbon reservoirs $[1-3,6$, 7]. There are many types of enhanced oil recovery methods based on the reservoir type, including conventional or unconventional, and the oil and gas properties $[8,9]$. One of the enhanced oil recovery methods that have several advantages due to its reaction with the reservoir is alkaline flooding. Alkaline flooding involves injecting a chemical agent into the reservoir with a high $\mathrm{pH}$ value in an attempt to create a surfactant downhole through reaction with the crude oil, which in turn can increase oil recovery by mobilizing the otherwise deemed irreducible oil.

Sherif Fakher is the primary author of the article and has conducted the experiments with the help of Hesham Abdelaal and Youssef Elgahawy. Abdulmohsin Imqam provided some help with the research.

Sherif Fakher, smfb96@mst.edu | 'Missouri University of Science and Technology, Rolla, MO, USA. ${ }^{1}$ University of Lisbon, Lisbon, Portugal. ${ }^{3}$ University of Calgary, Calgary, Canada. 
Many researchers have investigated alkaline injection to increase oil recovery. Chiwetelu et al. [10] investigated the feasibility of using several alkaline flooding agents, including sodium hydroxide, sodium metasilicate, and sodium orthosilicate, on increasing oil recovery from a heavy oil reservoir in Canada. Rincón-García et al. [11] studied the use of alkaline chemical agents to increase oil recovery from high-acidity crude oil. El-Sayed and Almalik [12] studied the effect of horizontal-vertical well configuration on oil recovery from the Safaniya Oil Field. Three alkalis were tested including sodium carbonate, sodium orthosilicate, and sodium hydroxide. Tagavifar et al. [13] researched the use of alkaline as a sacrificial chemical to reduce adsorption of other chemical enhanced oil recovery agents during injection. Cooke et al. [14] investigated the reaction of alkaline with the organic acids in the crude oil which resulted in the generation of surfactants that can help increase oil recovery by reducing interfacial tension between the oil and water. Mayer et al. [15] underwent a review of field tests and laboratory studies conducted using alkaline injection to determine the conditions at which this chemical enhanced oil recovery method was applied in both field and laboratory studies. Krumrine and Falcone [16] modified the proposed models that are used to model alkali consumption in the formation during alkaline flooding operations. Krumrine et al. [17] studied the scale precipitation due to alkaline reaction with some elements in the reservoir during alkaline enhanced oil recovery operations. It was observed that the hardness of the mixing water was one of the main reasons behind the creation of some of the precipitates. Southwick [18] investigated the loss of alkalinity created by the alkaline injection agent, usually sodium hydroxide, due to the dissolution of the alkaline with the silica in the formation, manifested mainly in the sand in the formation. Solutions to overcome this phenomenon were presented in this research in order to increase the usefulness acquired from the alkaline injection operation. Surkalo [19] provided a review on alkaline flooding principles and methods including different types of alkalis and the cost of a common alkaline injection operation.

Alkaline injection has also been coupled with other enhanced oil recovery methods including surfactant injection [20], polymer injection [21, 22], polymer and surfactant flooding [23-26], smart water injection [27], and even steam-assisted gravity drainage [28]. Potts and Kuehne [29] underwent experiments using fired Berea sandstone cores and reservoir cores to compare the difference between both when undergoing polymer/alkaline injection. It was found that higher concentrations of alkali were required for the reservoir cores compared to the Berea sandstone due to the prevention of chromatographic separation of the alkali and polymer injected. Flaaten et al. [30] applied a combined method of alkaline-surfactant-polymer flooding by using a form of borax that overcomes precipitation problems associated with chemical injection in the reservoir. Based on the experiment conducted, a formulation was found with the optimum salinity and total dissolved salts. Levitt et al. [31] studied the hydrolysis of polyacrylamide during alkaline-polymer injection and its impact on Injectivity. It was noticed that the injectivity of polyacrylamide was much better than that of hydrolyzed polyacrylamide since it had lower viscosity. Wu et al. [32] studied the applicability of alkaline-polymer injection in high-viscosity acidic crude oil. Lau [33] investigated the improvement of steam-foam generation and stability by injecting a specially formulated alkali-surfactant mixture in the aqueous phase of steam. Tests conducted included emulsion screening tests, corefloods, and flow visualization tests. Southwick et al. [34] observed that ammonia was much more preferable compared to sodium carbonate for alkaline surfactant and polymer flooding combined enhanced oil recovery due to its lower molar mass and its ability to be delivered easier due to its liquid state. Korrani et al. [35] underwent a mechanistic simulation study to investigate the reactions occurring during chemical enhanced oil recovery injection of combined alkaline surfactant and polymer injection. Wang et al. [36] performed geochemical modeling during alkaline-surfactant-polymer injection to study surfactant retention in limestone cores using sodium hydroxide alkaline solution. Kazempour et al. [37] reported the results of several coreflooding experiments that investigated the impact of alkalinity of the water on the performance of the polymer used during alkaline-polymer chemical enhanced oil recovery operations.

Most of the research conducted on alkaline flooding focused on two major aspects including either its ability to increase oil recovery, or its compatibility when being injected with other chemical enhanced oil recovery methods including polymer and surfactant, with little focus on the innate properties of the alkali agent itself and what factors may impact them. This research undergoes an experimental investigation of the properties of three alkali agents and the factors that may have a strong impact on them in order to investigate their applicability in oil reservoirs and the limitations that they may bear in an attempt to provide a better understanding of alkaline agents that can be used during alkaline flooding operations.

\section{Alkaline injection enhanced oil recovery mechanism}

Alkaline injection is a chemical enhanced oil recovery method that is used primarily to increase the microscopic oil recovery by the creation of in situ surfactants in the 
reservoir, thus reducing interfacial tension and altering rock wettability. The surfactant is created when the high$\mathrm{pH}$ alkaline chemical agent reacts with the acidic components of the crude oil [38]. This reaction is therefore highly dependent on two main factors. The first is the ability of the alkaline chemical agent to increase the $\mathrm{pH}$ significantly, especially in the presence of monovalent and divalent cations which are commonly present in the formation water. The second factor is the presence of an abundance of acidic components in the crude oil in order for the reaction between the chemical alkaline agent and the crude oil to take place. Another byproduct of some of the alkaline chemical agents' reaction is the generation of heat. This heat can result in the reduction in the crude oil's viscosity, which increases the oil's mobility and thus is an advantageous interaction as well. Based on this, understanding the ability of different alkaline chemical agents to increase $\mathrm{pH}$ in the presence of monovalent and divalent cations and their impact on temperature is crucial in determining the proper alkaline chemical agent to use during an alkaline injection operation.

\section{Experimental description}

Three sets of experiments were conducted to investigate the performance of three different alkaline chemicals, including sodium hydroxide, sodium silicate, and sodium carbonate when dissolved in distilled water, monovalent cations, and divalent cations. The experimental materials and the procedure followed to conduct all the experiments will be discussed in this section.

\subsection{Experimental materials}

The experimental materials used to conduct all the experiments in this research are mentioned and described in this section.

Sodium hydroxide Commercially available sodium hydroxide with high purity was used to conduct experiments. The chemical was provided as solid pellets. Sodium hydroxide is highly soluble in water, with a solubility of $111 \mathrm{~g} / 100 \mathrm{ml}$ of water at $20^{\circ} \mathrm{C}$.

Sodium silicate Sodium silicate was provided as a transparent liquid visually similar to water. The chemical had a purity of $99.99 \%$. Sodium silicate has a solubility of $22.2 \mathrm{~g} / 100 \mathrm{ml}$ of water at $20^{\circ} \mathrm{C}$.

Sodium carbonate The sodium carbonate used was a commercially available chemical and was provided as a powder with white color. Sodium carbonate has a solubility of $50.31 \mathrm{~g} / 100 \mathrm{ml}$ of water at $29.9^{\circ} \mathrm{C}$.
Distilled water Distilled water was used to conduct some of the experiments that did not involve any salts, and was also used to prepare the monovalent and divalent brine solutions.

Sodium chloride Chemical-grade sodium chloride was used to prepare the monovalent brine solution for all three alkalis.

Calcium chloride Calcium chloride was used to prepare the divalent brine solution for all three alkalis.

$\mathrm{pH}$ meter A high-accuracy $\mathrm{pH}$ meter was used to measure the $\mathrm{pH}$ for all the alkali solutions created at different conditions.

Thermometer A high-accuracy thermometer was used to measure the temperature change during the reaction of the alkali with the water and brine solutions.

Magnetic stirrer A magnetic stirrer was used to mix all the components of any solution homogenously to ensure that the measurements were as accurate as possible.

\subsection{Experimental procedure}

A predefined procedure was placed and followed for all the experiments conducted in order to be able to accurately compare the results. Each experiment conducted was repeated at least three times to ensure repeatability and accuracy. The exact procedure followed is presented below.

- Prepare the alkaline solution using $100 \mathrm{ml}$ of distilled water, or the brine solution, and then, add the alkaline chemical agent.

- Stir the solution using the magnetic stirrer for the duration of the experiment. This is to ensure that the solution is homogenous during the $\mathrm{pH}$ and temperature measurements.

- Measure the $\mathrm{pH}$ of the solution using the $\mathrm{pH}$ meter. The value taken for each experiment is recorded after the $\mathrm{pH}$ is stable for at least $30 \mathrm{~min}$.

- Record the temperature using both the $\mathrm{pH}$ meter and the thermometer to ensure that the temperature reading is accurate. The temperature is recorded after the reading is stable for $5 \mathrm{~min}$.

- Repeat each experiment at least three times to ensure that the values recorded were accurate and the experiment was repeatable. If the values did not match, all the experiments conducted for the specific variable were repeated until an accurate measurement is achieved.

- After each experiment was concluded, the beaker and equipment were washed using distilled water to avoid contamination from previous experiments and to avoid the impact of salts that many be present in the tap water. 


\section{Results and discussion}

The results for all the experiments conducted will be explained in this section. Initially, the impact of alkali concentration on the $\mathrm{pH}$ will be discussed for all the different alkali agents. Following this, the impact of monovalent and divalent cations on the alkali agents' performance will be discussed. The impact of the alkali agents on the temperature of the solution will also be explained. Finally, a comparison between the performances of all the alkali agents will be presented and explained.

\subsection{Alkali concentration impact on $\mathrm{pH}$}

The impact of altering the alkaline concentration in solution on the $\mathrm{pH}$ change for sodium hydroxide, sodium silicate, and sodium carbonate is presented in this section. The alkaline concentrations used for all three chemical agents include $4,3,2,1$, and 0.2 weight percent.

\subsubsection{Sodium hydroxide}

Sodium hydroxide is one of the most commonly used alkaline agents due to its ability to alter the $\mathrm{pH}$ of the crude oil and create in situ surfactants in the wellbore [39]. During its reaction with water, the sodium hydroxide dissociates into sodium and hydroxide, $\mathrm{OH}^{-}$, ions both of which are stable in water. The hydroxide ions are the main reason behind the increase in $\mathrm{pH}$. The exact reaction is shown below

$\mathrm{NaOH}+\mathrm{H}_{2} \mathrm{O}=\mathrm{Na}^{+}+\mathrm{OH}^{-}+$heat.

The effect of altering the sodium hydroxide concentration on the $\mathrm{pH}$ is presented in Fig. 1. All experiments were conducted at room temperature using distilled water. The red columns represent the initial $\mathrm{pH}$ of the water before adding the alkaline, while the black columns represent the final $\mathrm{pH}$ after adding the alkaline. Overall, the sodium hydroxide increased the $\mathrm{pH}$ of the solution by an average of $64 \%$. Increasing the sodium hydroxide concentration resulted in an increase in the $\mathrm{pH}$; however, the change was not extremely significant.

\subsubsection{Sodium silicate}

The second alkaline chemical agent used was sodium silicate. Sodium silicate has an advantage of being liquid at room temperature, and thus, it is much easier to inject compared to the sodium hydroxide or the sodium carbonate. The result of altering the sodium silicate concentration on the $\mathrm{pH}$ is shown in Fig. 2. All experiments were

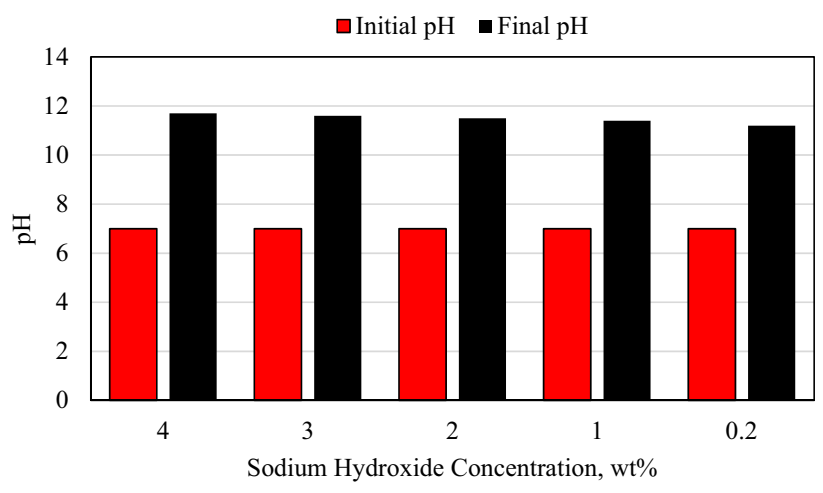

Fig. 1 Effect of sodium hydroxide concentration on $\mathrm{pH}$

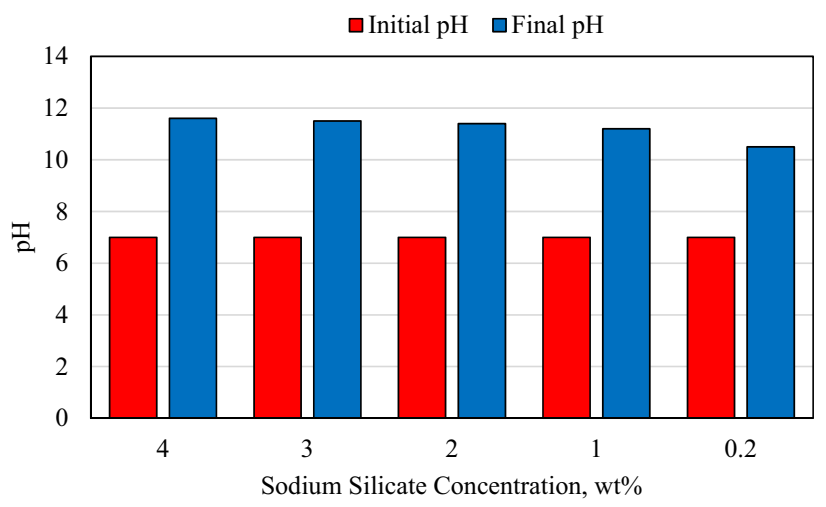

Fig. 2 Effect of sodium silicate concentration on $\mathrm{pH}$

conducted at room temperature using distilled water. Increasing the sodium silicate concentration resulted in an increase in the $\mathrm{pH}$. The lowest sodium silicate concentration, $0.2 \mathrm{wt} \%$, resulted in a much lower $\mathrm{pH}, 10.5$, compared to the $4 \mathrm{wt} \%$, which resulted in a pH of 11.6. Overall, the average $\mathrm{pH}$ increase was $62.4 \%$, which is slightly lower than the sodium hydroxide $\mathrm{pH}$ change.

\subsubsection{Sodium carbonate}

The final alkaline agent used in this study is sodium carbonate. When reacting with water, sodium carbonate will result in the generation of both an alkaline and an acid. This results in an overall low alteration of $\mathrm{pH}$. Initially, the sodium carbonate will dissociate into positive sodium ions and negative carbonate ions, as is shown in the equation

$\mathrm{Na}_{2} \mathrm{CO}_{3}+\mathrm{H}_{2} \mathrm{O} \stackrel{\text { yields }}{\rightarrow} 2 \mathrm{Na}^{+}+\mathrm{CO}_{3}^{2-}$.

Each of the sodium ions and the carbonate ions will then react with the water separately to form a new compound. The sodium will react with the water to form sodium hydroxide as is presented in the equation 
$2 \mathrm{Na}^{+}+\mathrm{H}_{2} \mathrm{O} \stackrel{\text { yields }}{\rightarrow} 2 \mathrm{NaOH}$.

The carbonate will react with the water and form carbonic acid, which is a weak acid. This reaction will also result in the release of hydroxide ions, which are stable in the water

$$
\begin{aligned}
& \mathrm{CO}_{3}^{2-}+\mathrm{H}_{2} \mathrm{O} \stackrel{\text { yields }}{\rightarrow} \mathrm{HCO}_{3}^{-}+\mathrm{OH}^{-} \\
& \mathrm{HCO}_{3}^{-}+\mathrm{H}_{2} \mathrm{O} \stackrel{\text { yields }}{\rightarrow} \mathrm{H}_{2} \mathrm{CO}_{3}+\mathrm{OH}^{-} .
\end{aligned}
$$

Even though the reaction results in the generation of both an alkaline and an acid, the overall $\mathrm{pH}$ will actually increase due to the larger concentration of hydroxide ions present.

The impact of altering the sodium carbonate concentration on the change in $\mathrm{pH}$ is shown in Fig. 3. All experiments were conducted at room temperature using distilled water. The overall change in $\mathrm{pH}$ is extremely low, especially when compared to the sodium hydroxide and the sodium silicate. This is mainly due to the negation of the impact of the generated sodium hydroxide by the carbonic acid. The average $\mathrm{pH}$ increase for the sodium carbonate experiments was $21.4 \%$.

\subsection{Monovalent cation impact on alkali pH}

The presence of monovalent cations in the water may impact the performance of the alkaline chemical agent due to the reaction of the salts with the alkaline agent. It is therefore important to investigate this impact since formation water will usually be associated with several dissolved salts, some of which are monovalent.

\subsubsection{Sodium hydroxide}

When dissolved in water, sodium hydroxide will dissociate into ions via an exothermic reaction. Since sodium

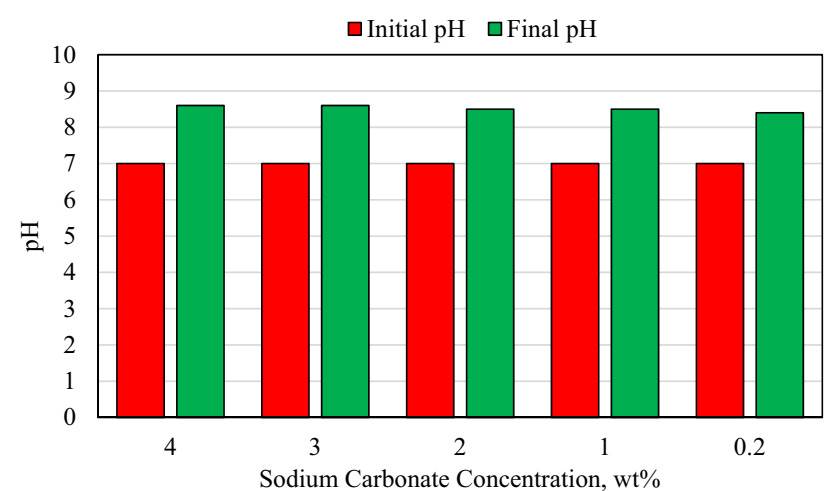

Fig. 3 Effect of sodium carbonate concentration on $\mathrm{pH}$ chloride is a salt and sodium hydroxide is a base, there is no reaction between both. The ions will dissociate in the aqueous medium and remain in solution. A precipitate may form if a high concentration of either chemical is added due to a restriction in solubility. The impact of altering the sodium chloride concentration on the sodium hydroxide $\mathrm{pH}$ alteration potential is shown in Fig. 4. All experiments were conducted at room temperature using $1 \mathrm{wt} \%$ sodium hydroxide. For all three sodium chloride concentrations, a significant $\mathrm{pH}$ change was observed. Increasing the sodium chloride concentration decreased the overall $\mathrm{pH}$ change. The $\mathrm{pH}$ increase for all three sodium chloride concentrations was 70,68.5, and $65.7 \%$ for the 1,5 , and 10 wt $\%$ sodium chloride, respectively.

\subsubsection{Sodium silicate}

When dissolved in the sodium chloride solution, the sodium silicate was found to be highly soluble. If the concentration of either chemical is increased in the water, a precipitate may form due to the limited solubility of the chemical agents. The result of altering the concentration of sodium chloride on the performance of the sodium silicate is shown in Fig. 5. All experiments were conducted at room temperature using $1 \mathrm{wt} \%$ sodium silicate. Increasing the sodium chloride concentration resulted in a slight decrease in the $\mathrm{pH}$. The lowest $\mathrm{pH}$ was associated with the $10 \%$ sodium chloride concentration, mainly due to the solubility restriction. The increase in $\mathrm{pH}$ for the 1,5 , and $10 \%$ sodium chloride was 60 , 57.1 , and $54.3 \%$, respectively. The increase in $\mathrm{pH}$ using sodium silicate was lower than that of sodium hydroxide, which is the same as was observed in the distilled water experiments.

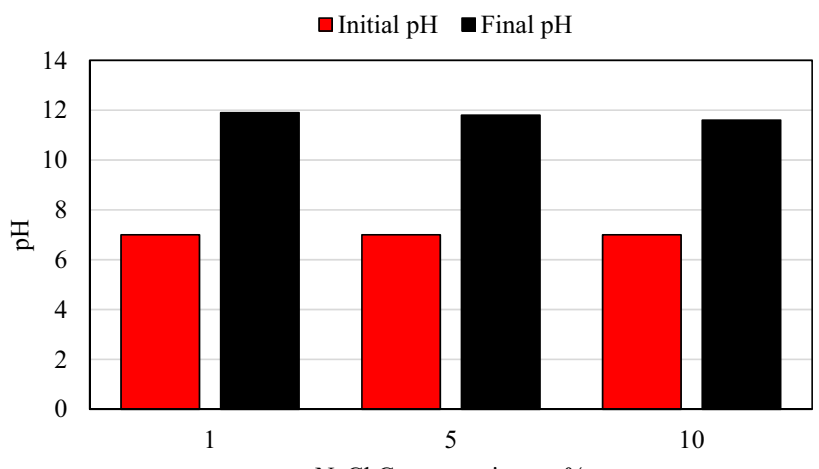

Fig. 4 Effect of monovalent cations on sodium hydroxide $\mathrm{pH}$ change 


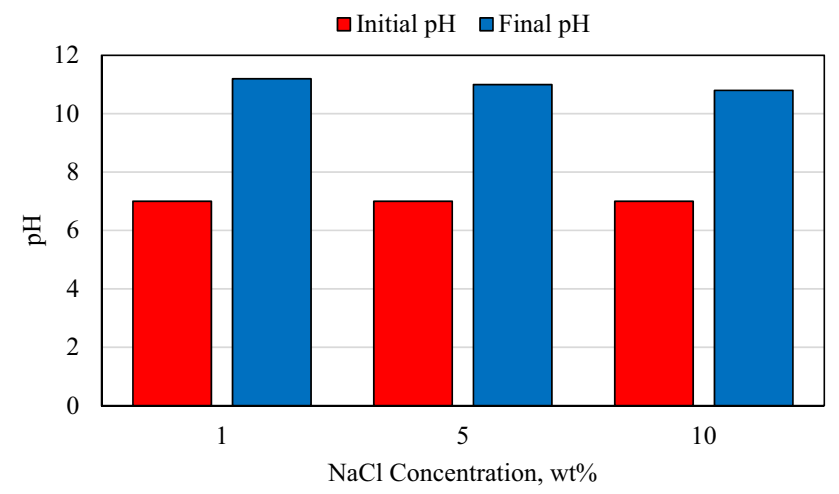

Fig. 5 Effect of monovalent cations on sodium silicate $\mathrm{pH}$ change

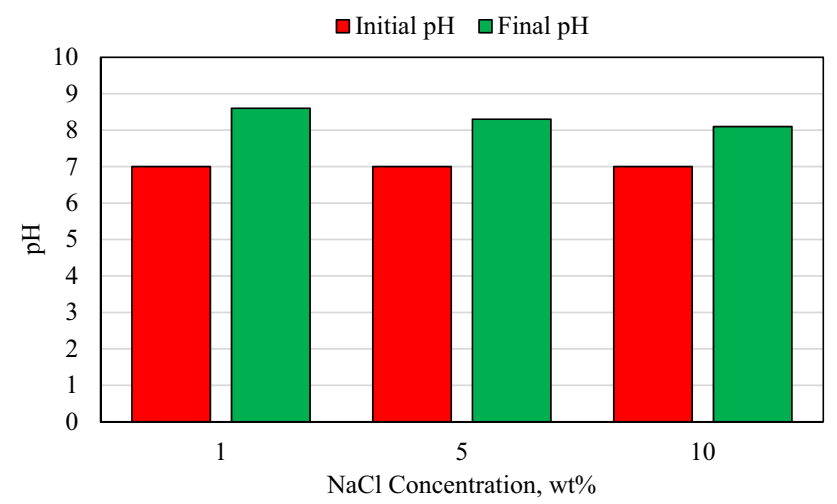

Fig. 6 Effect of monovalent cations on sodium carbonate $\mathrm{pH}$ change

\subsubsection{Sodium carbonate}

The impact of altering the sodium chloride concentration on the ability of sodium carbonate to alter the $\mathrm{pH}$ of the sodium carbonate is shown in Fig. 6 . All experiments were conducted at room temperature using $1 \mathrm{wt} \%$ sodium carbonate. Increasing the sodium chloride concentration resulted in a slight decrease in the $\mathrm{pH}$. The increase in $\mathrm{pH}$ for the 1,5 , and $10 \%$ sodium chloride solutions was 22.9 , 18.9 , and $15.7 \%$, respectively. Overall, the lowest increase in $\mathrm{pH}$ was observed when using sodium carbonate.

\subsection{Divalent cation impact on alkali pH}

Formation water may contain divalent cations that could have an impact on the performance of the alkaline agent. The divalent cations represent the hardness of the formation water. The impact of divalent cations on the performance of the sodium hydroxide, sodium silicate, and sodium carbonate was investigated using calcium chloride. All experiments were conducted at room temperature using $1 \mathrm{wt} \%$ calcium chloride.

\subsubsection{Sodium hydroxide}

When the sodium hydroxide was dissolved in the calcium chloride solution, the transparent brine solution changed color into white. This is due to the reaction of the sodium hydroxide with the calcium chloride to form calcium hydroxide. The calcium hydroxide is a white precipitate, and thus, the color of the solution should change to transparent again if the chemical is left to precipitate. An illustration of the white color obtained is shown in Fig. 7. The reaction between the sodium hydroxide and the calcium chloride is as follows

$2 \mathrm{NaOH}+\mathrm{CaCl}_{2} \stackrel{\text { yields }}{\rightarrow} 2 \mathrm{NaCl}+\mathrm{Ca}(\mathrm{OH})_{2}$.

The formation of calcium hydroxide may be unfavorable due to its nature as a precipitate. If it precipitates in the reservoir, the pores may be plugged, thus reducing the permeability, and therefore, oil recovery may also be reduced.
Fig. 7 Reaction of sodium hydroxide with calcium chloride

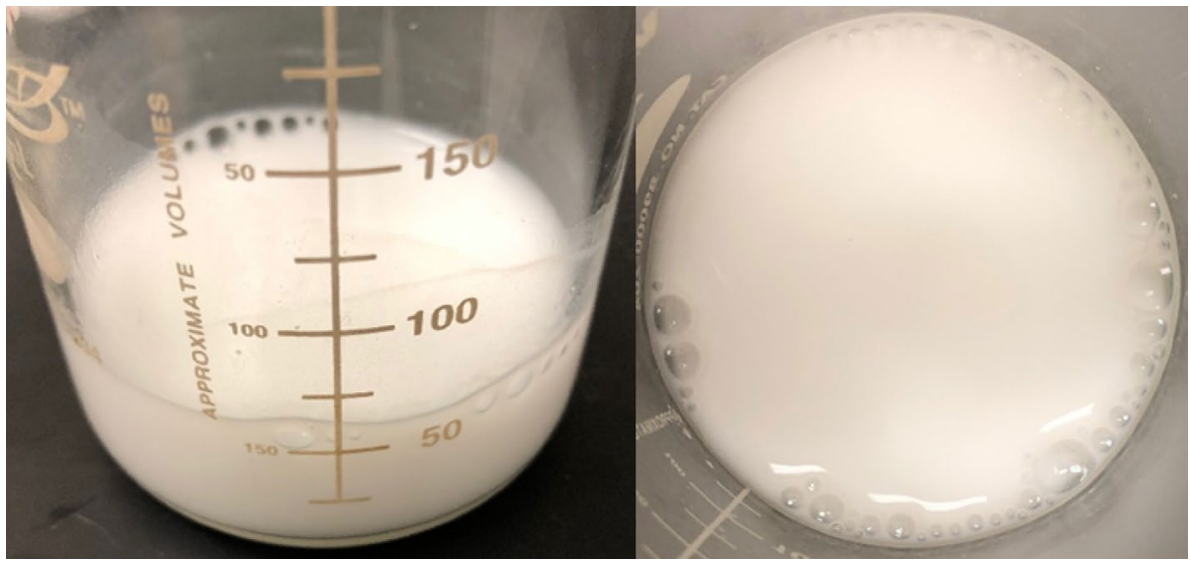


The impact of calcium chloride concentration on the performance of the sodium hydroxide is shown in Fig. 8. Increasing the calcium chloride concentration resulted in an increase in the solution $\mathrm{pH}$. This can be attributed to the formation of calcium hydroxide, which has a $\mathrm{pH}$ of 12.46 , for $100 \mathrm{mM}$. Increasing the calcium chloride concentration resulted in the formation of more calcium hydroxide and thus a higher $\mathrm{pH}$. The main drawback, however, is that the calcium hydroxide may precipitate and thus cause plugging problems during hydrocarbon production.

\subsubsection{Sodium silicate}

Sodium silicate reacted with the sodium chloride in the solution and formed a solid precipitate. The exact reaction between both is as follows

$\mathrm{Na}_{2} \mathrm{SiO}_{3}+\mathrm{CaCl}_{2} \stackrel{\text { yields }}{\rightarrow} \mathrm{CaSiO}_{3}+2 \mathrm{NaCl}$.

Based on the reaction, both sodium chloride and calcium silicate were formed when sodium silicate and calcium chloride reacted. Calcium silicate is a precipitate that resembles snowflakes. Figure 9 shows the formation

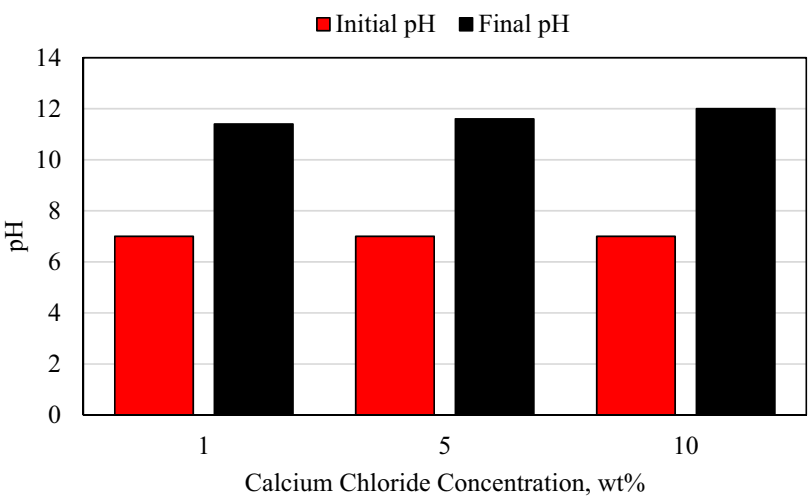

Fig. 8 Effect of divalent cations on sodium hydroxide $\mathrm{pH}$ change of sodium silicate after the reaction has taken place. The sodium silicate was consumed in the reaction to form calcium silicate and thus showed no impact on the $\mathrm{pH}$ change. Several attempts were made to measure the $\mathrm{pH}$ change; however, no significant alteration was observed. This could be due to the extremely rapid rate at which the calcium silicate was formed which resulted in no significant alteration of the solution $\mathrm{pH}$.

\subsubsection{Sodium carbonate}

When sodium carbonate was added to the calcium chloride solution, a small concentration of calcium carbonate precipitate formed. This precipitate could only be observed when the solution was left undisturbed for more than $2 \mathrm{~h}$. The exact reaction between sodium carbonate and calcium chloride is presented as follows

$\mathrm{CaCl}_{2}+\mathrm{Na}_{2} \mathrm{CO}_{3} \stackrel{\text { yields }}{\rightarrow} \mathrm{CaCO}_{3}+2 \mathrm{NaCl}$

The impact of altering calcium chloride concentration on the ability of the sodium carbonate to alter the $\mathrm{pH}$ is shown in Fig. 10. Increasing the calcium chloride concentration resulted in a decrease in the $\mathrm{pH}$. This could be explained by comparing the $\mathrm{pH}$ of sodium carbonate to the $\mathrm{pH}$ of calcium carbonate which was formed during the reaction of the sodium carbonate with the calcium carbonate. The $\mathrm{pH}$ of sodium carbonate is 11.26 , for $100 \mathrm{nM}$, while the $\mathrm{pH}$ of calcium carbonate is 9.91. Increasing the calcium chloride resulted in the generation of a larger volume of calcium carbonate, which has a lower $\mathrm{pH}$ compared to the sodium carbonate, and thus, the overall $\mathrm{pH}$ decreased with the increase in the calcium carbonate concentration.

\subsection{4 pH standard deviation}

The standard deviation for all the $\mathrm{pH}$ values obtained in all the experiments explained previously was calculated.
Fig. 9 Reaction of sodium silicate with calcium chloride

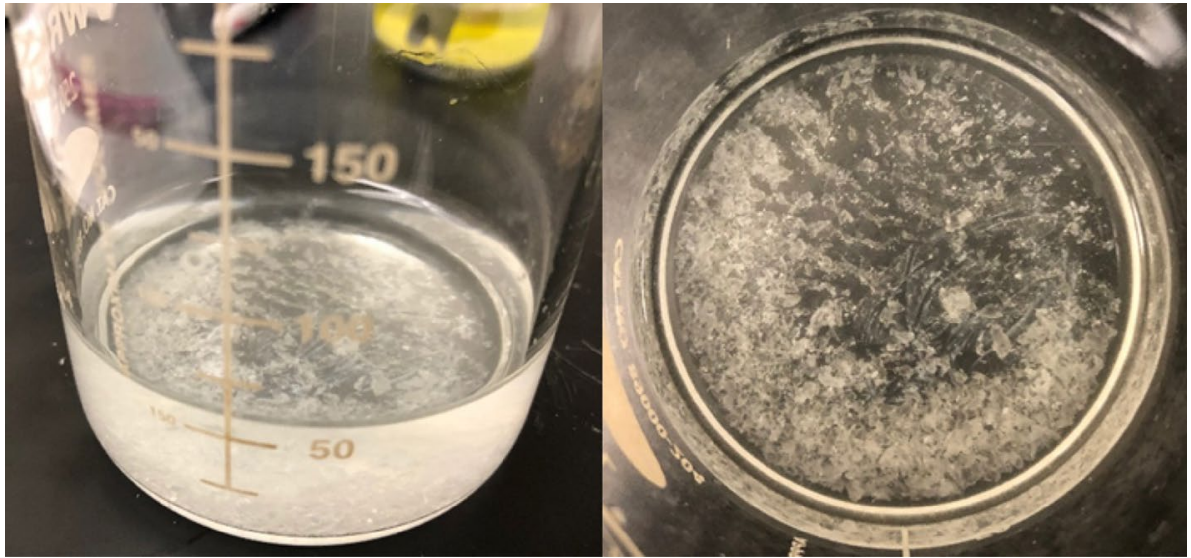

SN Applied Sciences A SPRINGER NATURE journal 


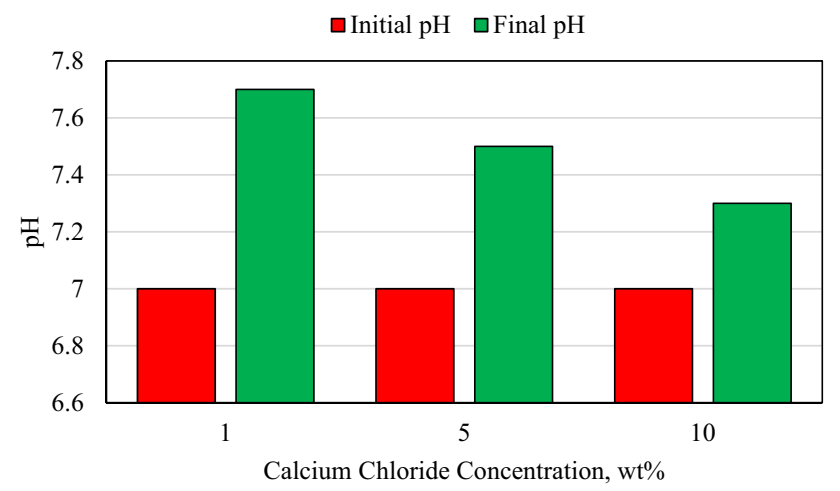

Fig. 10 Effect of divalent cations on sodium carbonate $\mathrm{pH}$ change

Table 1 Standard deviation for all $\mathrm{pH}$ values obtained

\begin{tabular}{llll}
\hline Solution type & Alkaline type & Mean & SD \\
\hline DI water & Sodium hydroxide & 11.48 & 0.192 \\
DI water & Sodium silicate & 11.24 & 0.439 \\
DI water & Sodium carbonate & 8.52 & 0.084 \\
Sodium chloride & Sodium hydroxide & 11.766667 & 0.153 \\
Sodium chloride & Sodium silicate & 11 & 0.200 \\
Sodium chloride & Sodium carbonate & 8.3333333 & 0.252 \\
Calcium chloride & Sodium hydroxide & 11.666667 & 0.306 \\
Calcium chloride & Sodium carbonate & 7.5 & 0.200 \\
\hline
\end{tabular}

Standard deviation can be an extremely useful value to indicate the extent to which the data deviate from the mean. This functions as a quality index for the data; a low standard deviation value shows that the data have a high accuracy. Table 1 shows the standard deviation values for all the experiments. As is shown, all the values are extremely low, thus indicating a high accuracy for the $\mathrm{pH}$ values obtained from the experiments.

\subsection{Alkali impact on temperature change}

During its reaction with the water, the alkaline may generate heat, if the reaction is exothermic. This heat generation can actually be advantageous in the reservoir since it may result in a reduction in oil viscosity, which will help increase oil mobility and thus increase oil recovery. The temperature change during sodium hydroxide, sodium silicate, and sodium carbonate reaction with distilled water, and the brine solutions will be presented in this section.

\subsubsection{Sodium hydroxide}

The temperature change during sodium hydroxide reaction with distilled water, sodium chloride, and calcium

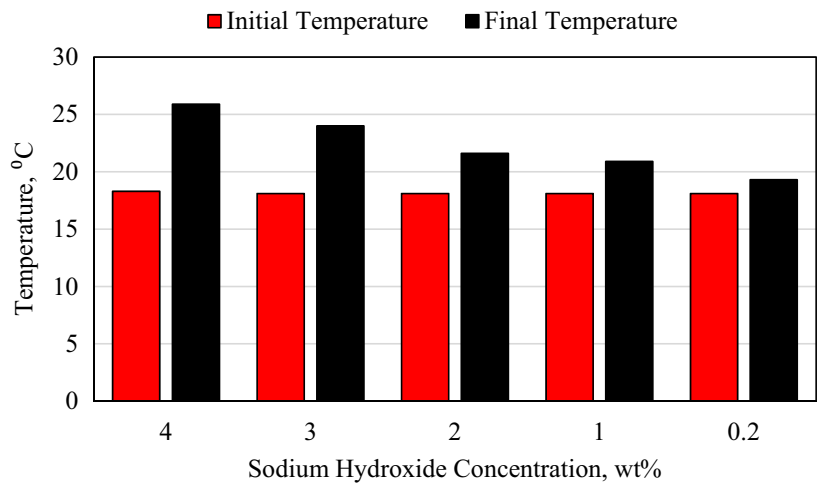

Fig. 11 Effect of sodium hydroxide on temperature change

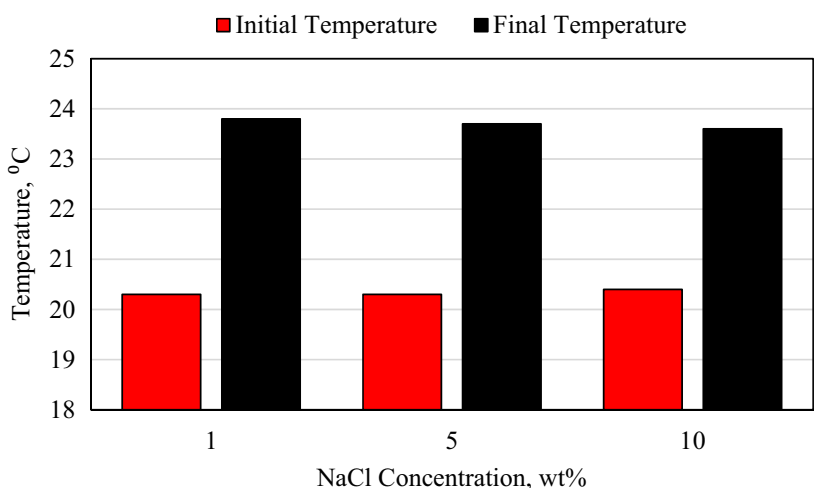

Fig. 12 Effect of monovalent cations on temperature change due to sodium hydroxide

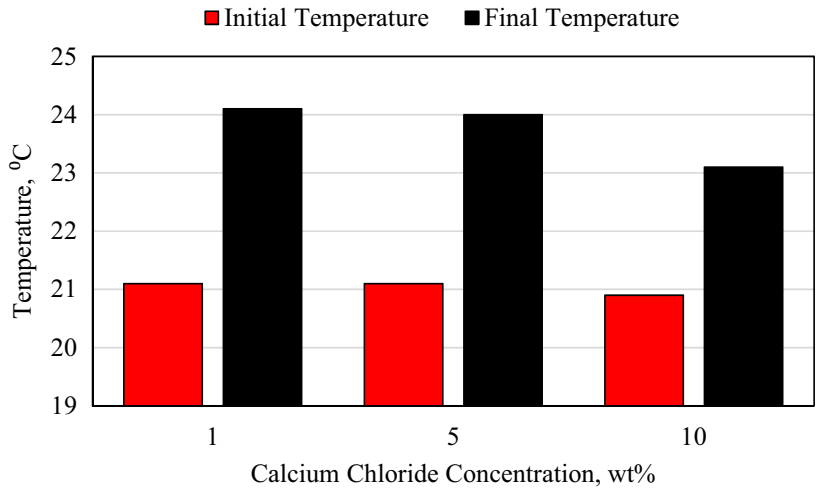

Fig. 13 Effect of divalent cations on temperature change due to sodium hydroxide

chloride is presented in Figs. 11, 12, and 13, respectively. The average initial temperature of the solution before adding the sodium hydroxide was $18.14^{\circ} \mathrm{C}$. Since sodium hydroxide reaction with water is exothermic, it was expected that increasing the sodium hydroxide 
concentration would result in a higher increase in temperature, as was seen from the experiments. The temperature increase for the $4,3,2,1$, and $0.2 \mathrm{wt} \%$ sodium hydroxide was $41.5,32.6,19.3,15.5$, and $6.6 \%$, respectiv ely.

When using sodium chloride, the temperature increase was slightly different. For the sodium chloride experiments, the sodium hydroxide concentration was $2 \mathrm{wt} \%$. The temperature increase for the 1,5 , and 10 wt $\%$ was $17.2,16.7$, and $15.7 \%$, respectively, which is slightly lower than the distilled water experiment for the $2 \mathrm{wt} \%$ sodium hydroxide.

The temperature increase for the calcium chloride was the lowest compared to all other experiments using sodium hydroxide. This could be due to the dissipation of some of the heat during the generation of calcium hydroxide. This is clear from the temperature results, where the rate of increase in temperature decreases with the increase in the calcium chloride concentration. The temperature increase for the 1,5 , and 10 wt $\%$ calcium chloride was $14.2,13.7$, and $10.5 \%$, respectively.

\subsubsection{Sodium silicate}

Figures 14 and 15 present the temperature change during sodium silicate reaction with distilled water and sodium chloride. The reaction with calcium chloride is not presented due to the incompatibility of the chemicals, as was explained previously in "Divalent cation impact on alkali $\mathrm{pH}^{\prime \prime}$ section. For both the distilled water and the sodium chloride experiments, there was no apparent trend for the change in temperature. This could be mainly due to the reaction not being exothermic, as compared to the sodium hydroxide reaction. The change in temperature observed in the results could be attributed to the excessive stirring of the solution, which may have generated some heat, or the change in room temperature slightly which was recorded on the thermometer due to its high accuracy.

\subsubsection{Sodium carbonate}

Temperature change due to the reaction of sodium carbonate with distilled water, sodium chloride, and calcium chloride is presented in Figs. 16, 17, and 18, respectively. As was the case with sodium silicate, there was no apparent trend for temperature change observed for the sodium carbonate. At higher concentrations of sodium carbonate, however, a slight temperature increase can be observed. This is attributed to the generation of a small concentration of sodium hydroxide which results in an exothermic reaction with the water, as was explained previously.

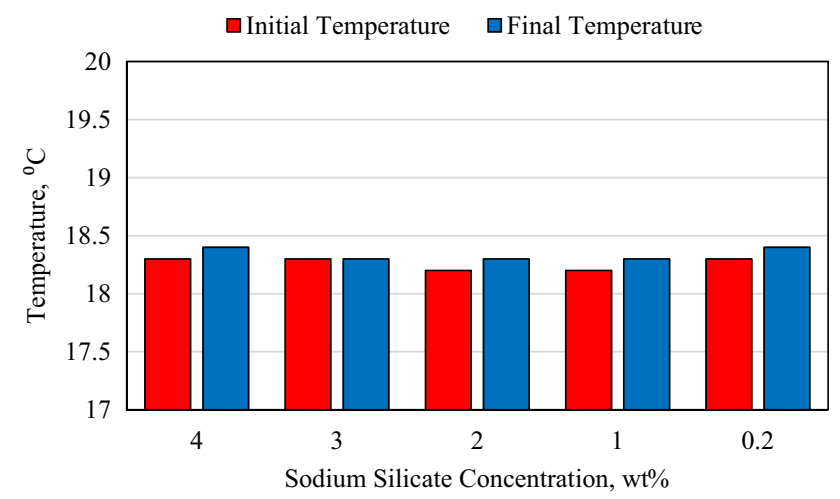

Fig. 14 Effect of sodium silicate on temperature change

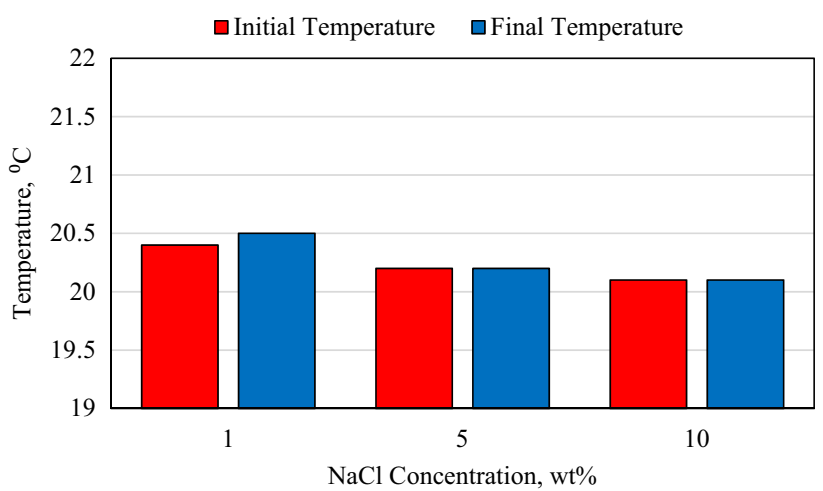

Fig. 15 Effect of monovalent cations on temperature change due to sodium silicate

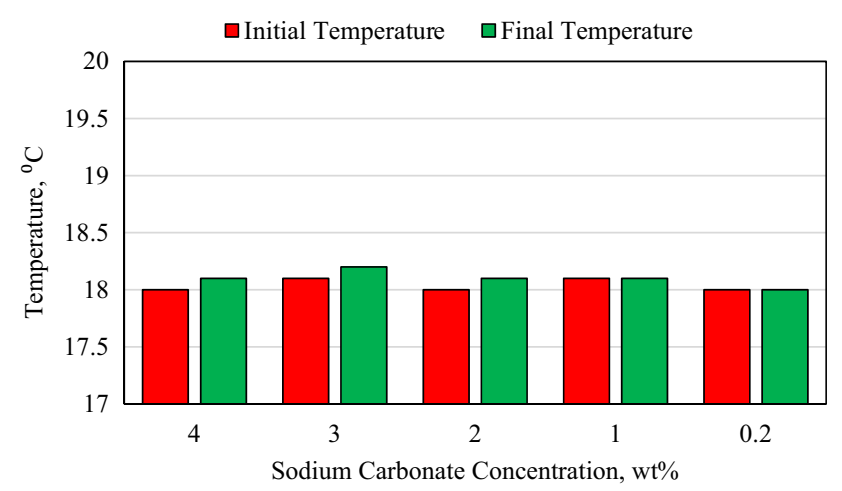

Fig. 16 Effect of sodium carbonate on temperature change

\section{Conclusion}

This research focuses on the properties of three common alkaline chemical agents, including sodium hydroxide, sodium silicate, and sodium carbonate, that are used during alkaline injection. The research investigates the 


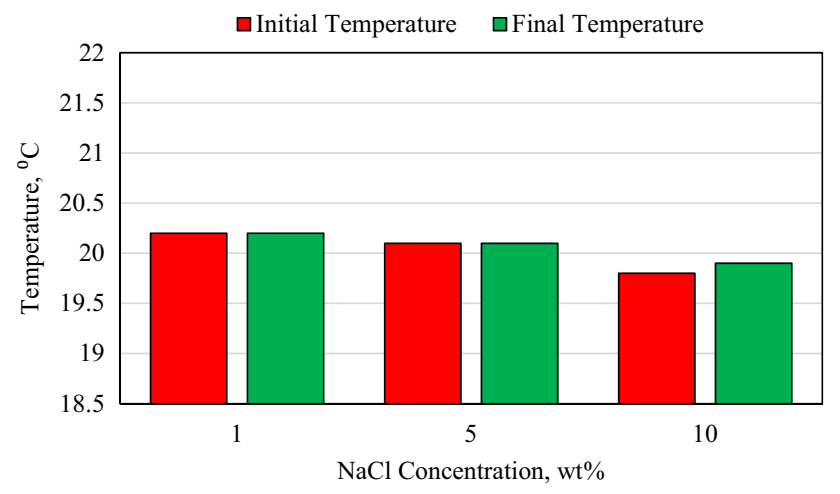

Fig. 17 Effect of monovalent cations on temperature change due to sodium carbonate

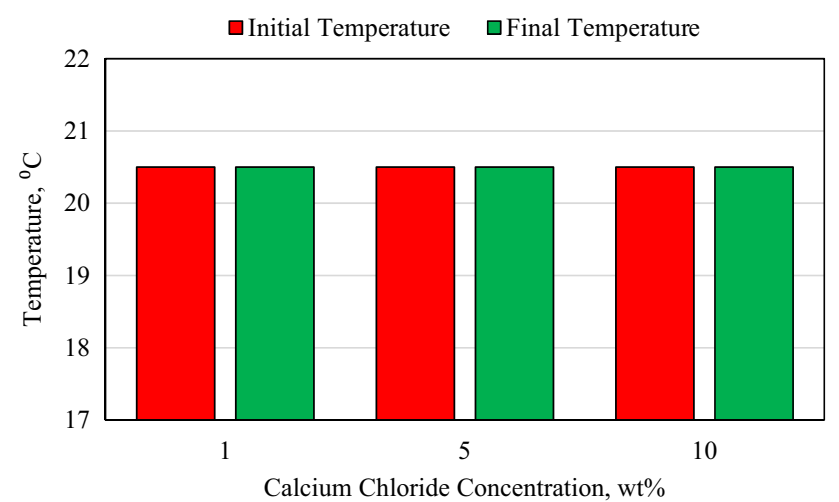

Fig. 18 Effect of divalent cations on temperature change due to sodium carbonate

chemical agents' performance in distilled water, monovalent cation solution, and divalent cation solution, and their ability to alter $\mathrm{pH}$ and temperature. The main conclusions obtained from this research are as follows.

- Increasing the concentration of all the alkaline agents resulted in an increase in the $\mathrm{pH}$, with the highest $\mathrm{pH}$ being observed for the sodium hydroxide, followed by sodium silicate, and finally the sodium carbonate.

- Sodium carbonate did not increase the pH significantly mainly due to the generation of sodium hydroxide and carbonic acid during its reaction with the water.

- The monovalent cation did not directly react with any of the three alkaline chemical agents used and thus did not create any new chemical agents during $\mathrm{pH}$ and temperature alteration.

- Divalent cations reacted with all three chemical agents and resulted in the generation of new chemicals. This in turn impacted the performance of the chemical agents significantly.
- Sodium silicate was not compatible with the calcium chloride, which indicates that formation water with a high concentration of divalent cations will have a strong impact on sodium silicate.

Acknowledgements The corresponding author would like to thank Missouri University of Science and Technology for its support through the Chancellor's Distinguished Fellowship.

\section{Compliance with ethical standards}

Conflict of interest All authors declare that they have no conflict of interest.

\section{References}

1. Fakher $S$ et al (2018) Investigating the viscosity reduction of ultra-heavy crude oil using hydrocarbon soluble low molecular weight compounds to improve oil production and transportation. Soc Petrol Eng. https://doi.org/10.2118/193677-MS

2. Fakher $S$ et al (2018) Increasing production flow rate and overall recovery from gas hydrate reservoirs using a combined steam flooding-thermodynamic inhibitor technique. Soc Petrol Eng. https://doi.org/10.2118/191179-MS

3. Fakher SM et al (2018) Enhancing carbon dioxide flooding sweep efficiency in high permeability hydrocarbon reservoirs using micro-particle gels. Soc Petrol Eng. https://doi. org/10.2118/192381-MS

4. Fakher SM (2019) Asphaltene stability in crude oil during carbon dioxide injection and its impact on oil recovery: a review, data analysis, and experimental study. Masters theses, p 7881

5. Fakher $S$ et al (2018) Reducing excessive water production associated with gas hydrate reservoirs using a thermal insitu heating-inhibitor method. Soc Petrol Eng. https://doi. org/10.2118/192382-MS

6. Fakher $\mathrm{S}$ et al (2017) Novel mathematical models to predict preformed particle gel placement and propagation through fractures. Soc Petrol Eng. https://doi.org/10.2118/187152-MS

7. Fakher $\mathrm{S}$ et al (2019) A comprehensive review on gas hydrate reservoirs: formation and dissociation thermodynamics and rock and fluid properties. Int Petrol Technol Conf. https://doi. org/10.2523/19373-MS

8. Fakher S, Imqam A (2018) Investigating and mitigating asphaltene precipitation and deposition in low permeability oil reservoirs during carbon dioxide flooding to increase oil recovery. Soc Petrol Eng. https://doi.org/10.2118/192558-MS

9. Fakher S, Imqam A (2019) Asphaltene precipitation and deposition during $\mathrm{CO}_{2}$ injection in nano shale pore structure and its impact on oil recovery. Fuel J 273:1029-1039. https://doi. org/10.1016/j.fuel.2018.10.039

10. Chiwetelu CL et al (1994) Recovery of a saskatchewan heavy oil using alkaline solutions. Petrol Soc Can 33(04):37-42. https:// doi.org/10.2118/94-04-05

11. Rincón-García H et al (2019) Enhanced oil recovery by means of alkali injection. Behavior of the SARA fractions. Petrol Sci Technol 37(21):2213-2222. https://doi.org/10.1080/10916 466.2019.1631343

12. El-Sayed AAH, Almalik MS (1995) Effect of horizontal-vertical well configuration on oil recovery by alkaline flooding. Petrol Soc Can 34(9):19-24. https://doi.org/10.2118/95-09-01 
13. Tagavifar $M$ et al (2018) Alkaline/surfactant/polymer flooding with sodium hydroxide in indiana limestone: analysis of water/ rock interactions and surfactant adsorption. Soc Petrol Eng 23(6):2279-2301. https://doi.org/10.2118/191146-PA

14. Cooke CE et al (1974) Oil recovery by alkaline waterflooding. Soc Petrol Eng 26(12):1365-1374. https://doi.org/10.2118/4739-PA

15. Mayer EH et al (1983) Alkaline injection for enhanced oil recovery-a status report. Soc Petrol Eng 35(1):209-221. https://doi. org/10.2118/8848-PA

16. Krumrine $\mathrm{PH}$, Falcone JS (1988) Rock dissolution and consumption phenomena in an alkaline recovery system. Soc Petrol Eng 3(1):62-68. https://doi.org/10.2118/12670-PA

17. Krumrine $\mathrm{PH}$ et al (1985) Scale formation during alkaline flooding. Soc Petrol Eng 37(8):1466-1474. https://doi. org/10.2118/12671-PA

18. Southwick JG (1985) Solubility of silica in alkaline solutions: implications for alkaline flooding. Soc Petrol Eng 25(6):857-864. https://doi.org/10.2118/12771-PA

19. Surkalo H (1990) Enhanced alkaline flooding. Soc Petrol Eng 42(1):6-7. https://doi.org/10.2118/19896-PA

20. Obuebite $A A$ et al (2019) Phase behavior of local alkaline and surfactants during flooding. Soc Petrol Eng. https://doi. org/10.2118/198772-MS

21. Fakher $\mathrm{S}$ et al (2020) Hydrolyzed polyacrylamide-fly ash reinforced polymer for chemical enhanced oil recovery: part 1-injectivity experiments. Fuel 260:11630. https://doi. org/10.1016/j.fuel.2019.116310

22. Schumi B et al (2019) Alkali/cosolvent/polymer flooding of high-TAN oil: using phase experiments, micromodels, and corefloods for injection-agent selection. Soc Petrol Eng. https://doi. org/10.2118/195504-pa

23. Abalkhail NA et al (2019) ASP flood application for a high-temperature, high-salinity carbonate reservoir. Soc Petrol Eng. https ://doi.org/10.2118/194948-ms

24. Al-Murayri MT et al (2018) One-spot oil de-saturation evaluation in the Sabriyah lower burgan sandstone formation testing an alkaline-surfactant formulation and interpretative translation to alkaline-surfactant-polymer oil recovery potential. Soc Petrol Eng. https://doi.org/10.2118/192781-ms

25. Phukan R et al (2019) Enhanced oil recovery by alkaline-surfactant-alternated-gas $/ \mathrm{CO}_{2}$ flooding. J Petrol Explor Prod Technol 9:247. https://doi.org/10.1007/s13202-018-0465-0

26. Zhong $\mathrm{H}$ et al (2019) Role of alkali type in chemical loss and asp-flooding enhanced oil recovery in sandstone formations. Soc Petrol Eng. https://doi.org/10.2118/191545-PA

27. Alabdullateef $\mathrm{M}$ et al (2019) Macroscopic scale interactions of smartwater with alkaline chemicals for enhanced oil recovery in carbonates. Soc Petrol Eng. https://doi.org/10.2118/198561-ms
28. Baek KH et al (2019) An experimental study of emulsion phase behavior and viscosity for athabasca bitumen/diethylamine/ brine mixtures. SPE Reserv Eval Eng 22(2):628-641. https://doi. org/10.2118/189768-pa

29. Potts DE, Kuehne DL (1988) Strategy for alkaline/polymer flood design with Berea and reservoir-rock corefloods. Soc Petrol Eng 3(4):1143-1152. https://doi.org/10.2118/14935-pa

30. Flaaten AK et al (2010) Alkaline/surfactant/polymer chemical flooding without the need for soft water. Soc Petrol Eng 15(01):184-196. https://doi.org/10.2118/116754-PA

31. Levitt DB et al (2011) Chemical degradation of polyacrylamide polymers under alkaline conditions. Soc Petrol Eng 14(3):281286. https://doi.org/10.2118/129879-PA

32. Wu Y et al (2011) Study of alkaline/polymer flooding for heavy-oil recovery using channeled sandpacks. Soc Petrol Eng 14(3):310-319. https://doi.org/10.2118/137460-PA

33. Lau HC (2012) Alkaline steam foam: concepts and experimental results. Soc Petrol Eng 15(4):445-452. https://doi. org/10.2118/144968-PA

34. Southwick JG et al (2016) Ammonia as alkali for alkaline/surfactant/polymer floods. Soc Petrol Eng 21(1):10-21. https://doi. org/10.2118/169057-PA

35. Korrani A et al (2016) A mechanistic integrated geochemical and chemical-flooding tool for alkaline/surfactant/polymer floods. Soc Petrol Eng 21(01):32-54. https://doi.org/10.2118/169094-PA

36. Wang $D$ et al (2019) Reduction of surfactant retention in limestones using sodium hydroxide. Soc Petrol Eng 24(1):92-115. https://doi.org/10.2118/194009-PA

37. Kazempour $\mathrm{M}$ et al (2012) Effect of alkalinity on oil recovery during polymer floods in sandstone. Soc Petrol Eng 15(02):195-209. https://doi.org/10.2118/141331-PA

38. Sheng J (2011) Modern chemical enhanced oil recovery. Gulf Professional Publishing, New York. https://doi.org/10.1016/ B978-1-85617-745-0.00018-8

39. Fortenberry R et al (2015) Use of cosolvents to improve alkaline/ polymer flooding. Soc Petrol Eng 20(02):255-266. https://doi. org/10.2118/166478-PA

Publisher's Note Springer Nature remains neutral with regard to jurisdictional claims in published maps and institutional affiliations. 